\title{
PSYCHIATRY AND THE SERVICEMAN'S FAMILY
}

\author{
Lieutenant-Colonel R. J. WAWMAN, M.B., Ch.B., M.R.C.Psych., D.P.M., R.A.M.C. \\ Cambridge Military Hospital, Aldershot *
}

\section{Introduction}

THE past 15 years have seen the transformation of our Armed Forces from a body of predominantly young unattached conscripts to one of more mature and predominantly married career servicemen (Wawman, 1968). Some have deplored this trend, but no practical alternative has emerged and it is now apparent that if the nation wishes to recruit and retain in the Forces sufficient men of ability it must recognise that in many respects the Armed Forces represent just one of a number of alternative careers which compete for the ambitious, married, skilled or semi-skilled worker.

At the same time as the serviceman has emerged as a family man it has also become apparent that the extent to which a man's employment interferes with his home life is a major factor in determining his attitude to and enthusiasm for that employment. DenshamBooth (1970) has remarked that "the influence of women in all aspects of family life is continually increasing". Others have commented that "in general . . . the soldier enjoys an active mobile life. It is the wife and children who suffer and who, if their burden is not eased "will by their unhappiness reduce his functioning efficiency or will even pursuade him to seek alternative employment" (Wawman, 1968). A situation now exists, in fact, where the services must accept that the welfare and morale of a soldier's family are no less important than his own.

For the psychiatrist who has recently learnt to regard a sick individual as the presenting member of a sick family (Howells, 1963) it may seem natural that the serviceman should not be considered in isolation from his family. For an employer, however, this is a new concept, and it is important to reflect that, like any other employer the Armed Forces are in contract with the man, not his family, and a tendency to view the family as an unproductive and costly grumbling appendix is, therefore, understandable.

The Armed Forces are not like other employers, however, in that the serviceman is " bound by contract to serve where, when and how the service demands" and is "a member of a rigidly structured and highly organised community in which his occupational, social and domestic lives are inextricably blended" (Wawman, 1968). Such an extreme state of dependency leads inevitably to a paternalistic attitude, not only towards the serviceman, but also towards his family. There emerges then a strong ambivalence on the part of the Armed Forces towards its families which is perhaps as intense as the ambivalence which the wives feel towards the service.

Many aspects of service life have been identified as stressful to service families: McGhie (1951); Fanning (1967); Congdon (1965); Wallis (1968), Wawman (1968); Hartog (1965); MacIntosh (1968); Dickerson (1965); Greenburg (1966); Murphy (Unpublished); O'Connor (1968); Densham-Booth (1970); Isay (1968); Britton (1970); Glen (1972), but as Wallis correctly emphasises " the most obvious and severe of these special stresses is separation of husband and wife", particularly when this occurs with great frequency, is of excessive duration, or when it occurs at critical times for the family

* Now Military Hospital, Tidworth, Hants. 
such as at times of illness or childbirth. However consciously loyal they may appear, many wives do not easily forget such desertion which may greatly affect their future attitudes both to their marriage and to service life.

Separation from parents, coupled with isolation in an unfamilar environment may particularly stress younger wives; whilst separation from school-age children is not always easily tolerated by older wives especially when the turmoils of adolescence call for parental support.

A further important stress is the nomadic existence which families must endure if they are to remain reasonably intact for any length of time. It may be argued that at the present time such nomadism is not uncommon in the civilian sector of the community. Perhaps this is so, but unlike his civilian counterpart the serviceman cannot be selective about his next move which may coincide with critical family events such as childbirth, serious illness in a close relative, or eleven-plus and G.C.E. examinations. Such disruption of schooling is often of considerable concern to the serviceman, and this may be particularly so when mental or physical handicap is involved for he cannot be sure either that adequate facilities will be available in his new station or that he can persuade a local authority to accept responsibility when he has no residential qualifications.

There are other stresses but separation and nomadism, to which should be added fear for the safety of a husband or father, are the most severe and it is particularly necessary to enquire whether these affect the mental health of the serviceman's family.

Congden (1965) has described Naval Families in Portsmouth as an " at risk" group with an increased liability to mental illness, whilst MacIntosh (1968) in his study of the problems of separation in America, also regarded military wives as a "special risk group". Some (Congdon, 1965) have suggested that service wives cope better in the absence of their menfolk if they return to the close support of relatives, but MacIntosh (1966) found that the majority of a group of separated wives treated by him were already living with or near relatives, and in many of them the return home was an important factor in the genesis of their illness.

Densham-Booth (1970) has reported a high incidence of neurotic symptomatology amongst service wives. Such findings are not always easy to interpret and DenshamBooth's are not dissimilar to those obtained by Taylor and Chave in their New Town Study (1964), which might indicate that such complaints are no more prevalent than in many other sections of our society. What is perhaps more disturbing is his finding that the group particularly prone to complain of neurotic symptoms was the younger wives with pre-school children, and this finding is supported by Fanning (1967) in his study of morbidity in service families in Germany.

Wallis (1968) in his survey of psychiatric morbidity in service families in Malta concluded that " most of the factors contributing to disturbance in service families are the same as for their civilian counterpart". Murphy on the other hand, in his account of psychiatric illness in general practice, said that " the special hazards of service life determine types of morbid psychological reaction in both the soldier and his family", whilst McGhie (1951), has noted that " problems associated with domestic disharmony, sexual problems, difficulties concerning the menopause and pregnancy, are sharpened by conditions existing in Overseas Communities". 


\section{Family stresses in an overseas military community}

In the presence of this uncertainty it might be useful to examine some of the aetiological factors apparently operating in a group of military wives who were sufficiently distressed to be referred for psychiatric advice and an analysis of the case histories of 50 consecutive wives referred in Singapore and Malaya in 1968 and seen by the author was, therefore, carried out. This revealed that a substantial proportion of them had a record of instability which often preceded any connection with the service environment. Thus 52 per cent had a seriously disturbed home background, whilst 46 per cent had received previous psychiatric treatment. Seventy per cent were considered to have some degree of instability of personality and in 28 per cent this emerged as the primary diagnosis. Even when the environmental stresses were considered it was found that although difficulty in adapting to the Far East was a presenting feature in 32 per cent, personality factors usually contributed to this and characteristic of the 12 per cent whose intolerance of the environment was extreme were obsessional and phobic traits.

Separation from kinfolk was an aetiological factor in the presentation of 16 per cent of whom two-thirds were young, newly-married women who had recently arrived in the Far East and given birth to their first child shortly before or after embarkation.

In only 18 per cent were the conditions of the husband's employment involving either frequent absence from home, shift work or risk to life considered to be important stresses, but it should be remembered that the Far East in 1968 was a relatively stable theatre with little separation or danger and virtually no financial hardship.

In 16 per cent the chronic disability or disordered behaviour of the wife substantially interfered with the serviceman's ability to discharge his duty effectively and in 8 per cent it was necessary to recommend the return to the United Kingdom (U.K.) of the whole family either in the interests of the wife's health or to relieve the administrative, welfare or medical services of a burden which they were not established to support.

The majority of cases presented acutely, however, and 50 per cent were seen only once. Many of the referrals confirmed McGhie's (1951) observations, that "families come within the sphere of the psychiatrist much more quickly in the Far East."

Relatively inexperienced general practitioners (G.Ps) and the rapid turnover of family doctors, nurses, welfare workers and population, led to the early referral of problems which in the U.K. would either have been dealt with by the G.P. himself or possibly referred to more appropriate agencies. Much of the psychiatrist's time was taken up, therefore, in giving advice to colleagues and briefing welfare agencies. McGhie's (1951) observations that in a closed community a domestic squabble is easily raised to the level of a major unit problem is pertinent as is the observation of Isay (1968) who, commenting in America on the aetiology of depression in submariners' wives, noted a frustration of dependency needs resulting from repeated absences of the husband from the home. This, he considered, led to a demanding dependent relationship with the physician. Such an attitude is often characteristic of service families generally and would indicate that the paternalistic attitude of the services is perhaps as much demanded by the families as imposed from above.

Isay (1968) viewed the depression which he observed as a guilty response to unacceptable rage at being deserted and to frustrated longing to be cared for adequately. He also 
pointed out that it served as a reproach to the husband, but, it might be added, it also serves as a reproach through the physician to the service, and thus emphasises the ambivalence which so many wives feel towards service life. This ambivalence is often heightened, as Densham-Booth (1970) has demonstrated, by the fact that isolation and nomadism often frustrate whatever aspiraion for a career a wife may have. This frustration is perhaps most obvious in the Far East where not only are work permits difficult to obtain but even the career of housewife is threatened by the presence in the wife's domain of domestic servants.

Many wives are unprepared for enforced idleness and the resultant frustration and guilt is not infrequently increased by the fact that now they are freed from the burden of household drudgery their husbands expect a standard of domestic efficiency and social grace which may be beyond them. Marital disharmony and depression commonly stem from this mechanism, but fortunately tend to respond to simple explanation, reassurance and-in a few cases only-dismissal of the servants.

Most wives of career servicemen come to accept the love/hate relationship with service life partly because of the compensations which the life offers in terms of travel and material security, but primarily because of identification with their husbands and the service. It is perhaps not surprising, therefore, that the groups which appear to have the greatest problems of adjustment are young wives newly introduced to service life and the wives of men whose service life will shortly be coming to an end.

The first group, although presenting dramatically, rarely needs more than the minimum of treatment and responds rapidly and well to encouragement and social support. The second group, as Greenburg (1966) has shown, no longer identifies with the service which their husbands are soon to leave. Their status, security and self-esteem are all threatened at a vulnerable time of life; indeed the frustration of their needs to plan and work for a new life gives an added sense of insecurity. Under these circumstances hostility towards and intolerance of all things service become manifest and they may fail to adjust to this last overseas tour. Usually they can be assisted by supportive treatment, but full resolution of symptoms cannot be expected until they are finally settled in civil life.

The conclusions to be drawn so far from this examination of psychiatric problems in service families are:-

a. The married soldier forms the backbone of the Armed Forces.

b. The Serviceman and his family form an indivisible unit which should be regarded as such.

c. Although some of the problems presented by service families may have their basis in personality weakness, service life poses special problems for families which require special attention.

\section{Mental health services for families in the Far East}

What part should the mental health services of the Armed Forces play in this special attention and how should they be organised? The present structure of the Army Psychiatric Services derives from the requirements of World War II and National Service. With reduction in the size of the Army, the Psychiatric Services have also shrunk but have remained either hospital or office based and serviceman orientated. Involvement 
with families has tended to be incidental except in Overseas Theatres where comprehensive and community based services have slowly evolved. Thus whilst McGhie in 1951 treated more than 50 per cent of his Far East patients in hospital, in 1968 the figure was 20 per cent, the admissions were brief and every effort was made to maintain and treat patients in the community. In fact support from social welfare agencies was recommended in 62 per cent of the cases covered in the 1968 Far East Survey and this was reflected by the fact that the psychiatrists found themselves increasingly involved in an advisory and co-ordinating role with the various social agencies.

A serious obstacle to the formation of the necessary links, however, was the rapid turnover of G.P., Specialist, Social Worker, Unit Officer and patient. No sooner was a working relationship established than it came to an end and new links had to be patiently created so that, if the various social agencies were not to remain isolated and unco-ordinated, a positive and sustained effort was required.

Another problem was that until comparatively recently the Army had no Psychiatric Social Worker outside the Royal Victoria Hospital, Netley, and in the absence of that member of the psychiatric team, who would normally forge these links, this role devolved on the psychiatrist whose ability to fulfil it was limited by the weight of clinical and other commitments which sometimes claimed priority. During the past 5 years Psychiatric Social Workers have in fact been appointed to the Child Guidance Clinics which have been established in overseas theatres including the Far East, but adult psychiatry in that theatre remains devoid of this professional assistance.

However, at informal meetings sponsored by the psychiatrists the various Far East welfare agencies recognised the importance of co-ordination and closer contact together with the needs for a central registry of social problems, easy access to specialist advice and the establishment of a marriage guidance service. The psychiatric services were considered the most appropriate to provide co-ordination of the social services and to this end a member of the nursing staff was removed from in-patient work and assigned to work under supervision as a social welfare assistant with special responsibilities for the formation of a central register, and the provision of an effective link with other social and administrative agencies.

The principal agencies with which the psychiatrist had liaison in the Far East were the Child Guidance Team, S.S.A.F.A. Welfare Officers, S.S.A.F.A. Nursing Sisters, Padres, Medical Officers and last, but by no means least, Unit Officers whose ultimate responsibility for a soldier's welfare problems has recently been re-affirmed by the Ministry of Defence.

Close liaison with the Child Guidance Team was easily fostered by the fact that the Child Psychiatrist also worked in the field of adult psychiatry. A close relationship with the S.S.A.F.A. Welfare Officers was also established. Their limited numbers, however, and responsibility for a very wide range of welfare problems considerably limited their ability to become involved in psychiatric case work for any length of time. Often the people most able to offer support were the S.S.A.F.A. Nursing Sisters whose role of health visitor brought them into very close contact with both G.P. and family. They are not trained social workers, however, and are not encouraged by their terms of reference to become involved in marital problems although many of them, when adequately supervised, had much to offer in this area. 
It was in the realm of marriage guidance that the psychiatrist in the Far East found the social services most lacking. Serious marital discord, not obviously related to service stresses, existed in 30 per cent of the cases in the 1968 Survey and some form of marriage guidance was indicated in two-thirds of these. Guidance of a sort was variously provided by whatever social agency happened to become involved. Sometimes help was sought outside the service setting, but often it was just not available. In any case it tended to be variable in its form and efficacy and was on occasion more harmful than beneficial. An approach to the National Marriage Guidance Council for the names of any counsellors who might be with the Forces in the Far East led to contact with one who was also an experienced tutor and incidentally the senior Royal Air Force Padre in the Far East. This was fortunate for whilst problems of finance, accommodation, lack of clerical assistance and the inertia of some administrative and welfare quarters made the rapid establishment of a medically sponsored marriage guidance service unlikely, it quickly emerged that support and facilities for a supervised non-directional counselling set-up with in-service training would be forthcoming from the service padres who had, in any case, hitherto shouldered a major part of this burden.

It was with the padres, therefore, that an effective and still thriving (Cannan 1970) counselling service was established in the belief that whilst the run-down East of Suez might prevent the further expansion of this particular service, it would nevertheless serve as a model for wider based marriage guidance services which could be established in other theatres.

\section{Mental health and families in the United Kingdom}

It will be apparent that not only is a comprehensive community based psychiatric service desirable in an overseas theatre but that it can, with a little ingenuity and some effort, be established. What bearing, if any, does this have on service psychiatry in the U.K.?

In the U.K. our psychiatry remains serviceman orientated and even in the larger garrison areas we largely exclude the families who became the responsibility of the local psychiatric and social services. In the past such a situation although in many respects unsatisfactory, was accepted and appeared to work. Whether it will do so effectively in the future, when less families will be able to enjoy overseas tours and more families will remain in the U.K. while their menfolk proceed overseas unaccompanied, is a matter of some doubt, for the special problems of service families are likely to be aggravated by these developments.

Perhaps it would be in the interest of all concerned if service psychiatrists, who might be expected to have special knowledge of the stresses of service life and of the realistic avenues which are available for their alleviation, were actively involved in the management of psychiatric disorders in service families. The extent of the involvement which is considered practical will be governed by financial consideration, and it is likely that the establishment of a comprehensive and independent service even in the largest garrison area would be impractical in view of the relatively limited numbers involved. The solution perhaps lies, as Densham-Booth has suggested for the welfare services, in the partial integration of a modestly expanded and re-deployed service psychiatric set-up with the local psychiatric services. 
It is suggested that a more economical utilisation of the in-patient facilities provided by the three services could be the first step in this re-organisation. A reduction in the total staff required to administer the Royal Navy and Army Psychiatric Services has already been achieved by the amalgamation of the in-patient units of those services at Netley. The planned movement of this combined unit from its present isolated if idyllic location to become a wing of a new general hospital in Aldershot could have two further beneficial effects. In the first instance it would allow the staff of that unit to become involved in family psychiatry and thus significantly improve its training facilities whilst incidentally providing a comprehensive psychiatric service for one garrison area. Secondly it would effect further economies of trained medical and nursing staff. The staff freed from in-patient work, possibly augmented by a modest increase in establishment could be re-deployed in association with their colleagues already established in the various U.K. Commands.

This re-deployment, together with the establishment of Honorary Consultant appointments to local mental hospitals in large garrison areas, would go a long way towards helping service psychiatrists absorb the increased case load which accepting responsibility for service families would entail, but what of the social worker so necessary to a community based service?

Recently agreement has been reached for a small number of selected Army psychiatric nurses to be trained in social work and it is intended eventually to utilise these uniformed "mental health technicians" as psychiatric social workers. This is a significant departure for British military psychiatry and one in the right direction, but it may be that the present involvement is not nearly enough and that much larger numbers of service psychiatric nurses, as made available by the streamlining of in-patient units and the close down of overseas theatres, should be trained and then utilised as social workers in a community based service.

They would work under the supervision of the service psychiatrist, but in close collaboration with local mental welfare officers, and would actively establish links between other welfare agencies and service units thus ensuring that these resources would be readily available to the military community.

\section{Conclusion}

The Seebohm Report (1968) states: "We are convinced that designated areas of special need should receive extra resources comprehensively planned in co-operation with services both central and local concerned with health, education, housing and other social needs." A case is made in this paper for regarding the Families of Servicemen as just such a "designated area". Perhaps what is proposed as a possible means of providing " the extra resources comprehensively planned ". is too simple in that it does not look closely enough at economic and man-power considerations and does not take into account the resistance likely to be encountered in some quarters. Nevertheless it is suggested that some re-organisation of our resources is necessary and that these changes, if made, would increase the effectiveness of the British Military Psychiatric Services and enable them to adopt a more rational and functional attitude towards the stress of service life in the 1970's. 


\section{REFERENCES}

Britton, R. S. (1969). J. Child Psychol. 10, 245.

CANNAN, E. A. C. (1970). Assistant Chaplain-in-Chief, H.Q., F.E.C., R.A.F. (Personal communication). Congdon, R. G. (1965). Towards Community Care. City of Portsmouth Mental Health Service.

Densham-Booth, B. F. (1970). Social Planning the 1970's-80's. A Sociological Study of the Human Environment relating to Soldiers' Families. Defence Fellowship 1968-69.

DiCKerson, W. and ARTHUR, R. (1965). Milit. Med. 130, 894.

FANNING, D. M. (1967). Brit. med. J. 4, 382.

GLEN, D. W. F. (1972), J. roy. Army med. Corps 118, 135.

Greenburg, H. (1966). Amer. J. Psychiat. $123,487$.

Hartog, J. (1966). Amer. J. Psychiat. 122, 1125.

Howells, J. G. (1963). Family Psychiatry. Oliver \& Boyd. Edinburgh.

ISAY, H. A. (1968). Psychiat. Quart. 42, 647.

McGHIE, J. F. and MCConvele, D. J. (1953). J. roy. Army med. Cps 99, 228.

Macintosh, H. (1968). Amer. J. Psychiat. 125, 260.

MURPHY, J. F. D. (-). Psychiatric Illness in General Practice (Unpublished).

O'ConNor. P. J. (1968). Proc. roy. Soc. Med. 61, 973.

Report of the Committee on Local Authority and Allied Personal Social Services (1968). H.M.S.O. London.

TAYLOR, Lord and Chave, S. (1964). Mental Health and Environment. Longman's. London.

Wallis, G. G. (1968). Proc. roy. Soc. Med. 61, 976.

WAWMAN, R. J. (1968). Proc. roy. Soc. Med. 61, 979.

\section{Senior Appointments}

Brigadier R. G. MacFarlane, M.B.E., M.D., F.R.C.P., to be Director of Army Medicine and Consulting Physician to the Army, in April 1973 in the rank of MajorGeneral.

Brigadier Robert Goudie MacFarlane, aged 55 years, was born in Glasgow and educated at Hillhead High School and Glasgow University, graduated M.B., Ch.B., in 1940 and joined the Royal Army Medical Corps in the following year.

During the second world war he served in Madagascar, India and South-East Asia.

He became Joint Professor of Military Medicine at the Royal College of Physicians and the Royal Army Medical College in January 1970 and in May 1971 took up his present appointment as Consulting Physician, British Army of the Rhine.

$\mathrm{He}$ is married and has three children.

Brigadier T. W. Carrick, O.B.E., M.B., F.F.C.M., D.P.H., D.I.H., Director of Army Health and Research, to be Commandant and Director of Studies, Royal Army Medical College, in March 1973, in succession to Major-General J. P. Baird, Q.H.P., M.D., F.R.C.P., F.R.C.P. (Ed.)

A note on his career was published in the Journal, Volume 117, No. 2, 1971. 